\title{
Overexpression of Forebrain CRH During Early Life Increases Trauma Susceptibility in Adulthood
}

\author{
Mate Toth ${ }^{1,2}$, Elizabeth I Flandreau ${ }^{1,2}$, Jessica Deslauriers ${ }^{1,2}$, Mark A Geyer ${ }^{1,2}$, Isabelle M Mansuy ${ }^{3}$, \\ Emilio Merlo Pich ${ }^{4}$ and Victoria B Risbrough ${ }^{*, 1,2}$
}

'Department of Psychiatry, University of California San Diego, La Jolla, CA, USA; ${ }^{2}$ Center of Excellence for Stress and Mental Health, Veterans Affairs, La Jolla, CA, USA; ${ }^{3}$ Laboratory of Neuroepigenetics, Center for Neuroscience Zürich, Brain Research Institute, University of Zürich and ETH Zürich, Zürich, Switzerland; ${ }^{4}$ Division of Brain Sciences, Department of Medicine, Imperial College, London, UK

\begin{abstract}
Although early-life stress is a significant risk factor for developing anxiety disorders, including posttraumatic stress disorder (PTSD), the underlying mechanisms are unclear. Corticotropin releasing hormone $(\mathrm{CRH})$ is disrupted in individuals with PTSD and early-life stress and hence may mediate the effects of early-life stress on PTSD risk. We hypothesized that CRH hyper-signaling in the forebrain during early development is sufficient to increase response to trauma in adulthood. To test this hypothesis, we induced transient, forebrain-specific, $\mathrm{CRH}$ overexpression during early-life (pre-puberty, $\mathrm{CRHOE}_{\text {dev }}$ ) in double-mutant mice (Camk2a-rtta2 $\times$ tetO-Crh) and tested their behavioral and gene expression responses to the predator stress model of PTSD in adulthood. In one cohort of CRHOE $\mathrm{E}_{\text {dev }}$ exposed and unexposed mice, avoidance and arousal behaviors were examined 7-15 days after exposure to predator stress. In another cohort, gene expression changes in Crhrl, Crhr2, and Fkbp5I in forebrain of $\mathrm{CRHOE}_{\text {dev }}$ exposed and unexposed mice were examined 7 days after predator stress. $\mathrm{CRHOE}_{\mathrm{dev}}$ induced robust increases in startle reactivity and reductions in startle inhibition independently of predator stress in both male and female mice. Avoidance behaviors after predator stress were highly dependent on sex and $C R H O E_{\text {dev }}$ exposure. Whereas stressed females exhibited robust avoidance responses that were not altered by $\mathrm{CRHOE}_{\text {dev, }}$ males developed significant avoidance only when exposed to both $\mathrm{CRHOE}_{\text {dev }}$ and stress. Quantitative real-time-PCR analysis indicated that $C R H O E_{\text {dev }}$ unexposed males exhibit significant changes in Crhr2 expression in the amygdala and bed nucleus stria terminalis in response to stress, whereas males exposed to $\mathrm{CRHOE}_{\text {dev }}$ did not. Similar to $\mathrm{CRHOE}_{\text {dev }}$ males, females exhibited no significant Crhr2 gene expression changes in response to stress. Cortical Fkbp5I expression was also significantly reduced by stress and $\mathrm{CRHOE}_{\text {dev }}$ exposure in males, but not in females. These findings indicate that forebrain CRH hyper-signaling in early-life is sufficient to increase enduring effects of adult trauma and attenuate Crhr2 expression changes in response to stress in males. These data support growing evidence for significant sex differences in response to trauma, and support further study of CRHR2 as a candidate mechanism for PTSD risk.

Neuropsychopharmacology (2016) 4I, I68I-1690; doi: I 0.I038/npp.20 I5.338; published online 9 December 2015
\end{abstract}

\section{INTRODUCTION}

The significant contrast between lifetime trauma incidence and the prevalence to develop PTSD (40-70\% vs 7-10\%, respectively; Kessler et al, 2010) supports the importance of identifying underlying mechanisms of stress vulnerability. Genetic studies have documented significant heritability of anxiety and stress vulnerability, implicating several genes as potential risk factors including CRH (Heim and Nemeroff, 2001; Skelton et al, 2012; Smoller et al, 2003). However, the causal role of these candidates and underlying mechanisms are still not clarified. By exhibiting high plasticity and intense maturation in limbic regions, developmental periods exhibit

*Correspondence: Dr $\vee$ Risbrough, Department of Psychiatry, University of California San Diego, 9500 Gilman Dr MC0804, La Jolla, CA 92093-0804, USA, Tel: +16195433582, Fax: +16195432475, E-mail: vrisbrough@ucsd.edu

Received 25 March 2015; revised 30 September 2015; accepted 29 October 20 I5; accepted article preview online 5 November 2015 significant vulnerability for stress, and accordingly can lead to profound changes in the structure and function of these regions, eg, decreased volume of the hippocampus, and altered amygdala-prefrontal functions, which are considered significant risk factors for PTSD (Dannlowski et al, 2012; Heim and Nemeroff, 2001). Early-life stress may also induce latent alterations in brain development with functional consequences that are only precipitated by additional stress in later life (Hammen et al, 2000). Although multiple factors are likely involved in the mediation of early-life effects on neuropsychiatric risk, major coordinators of the stress response including HPA-axis elements such as glucocorticoid receptor, its binding protein FKBP5, and CRH signaling elements are primary neurobiological candidates in the pathogenesis of PTSD (Skelton et al, 2012).

Significant evidence suggests that $\mathrm{CRH}$ has a role in this process as the central coordinator of the stress response. For instance, $\mathrm{CRH}$ is elevated in the cerebrospinal fluid of patients diagnosed with PTSD and individuals with significant childhood trauma history (Bremner et al, 1997; 
Carpenter et al, 2004; Lee et al, 2005). Moreover, CRH receptor type 1 ( Crhrl) polymorphisms moderate associations of childhood trauma with depression and anxiety (Bradley et al, 2008; Cicchetti et al, 2011). Rodent and primate studies also showed that early stress increases $\mathrm{CRH}$ concentration in the cerebrospinal fluid and limbic brain regions (Coplan et al, 1996; Plotsky et al, 2005) where CRH has been shown to modulate PTSD-related phenotypes (Radulovic et al, 1999; Regev et al, 2012).

Based on the above findings, we hypothesized that $\mathrm{CRH}$ hyper-signaling during development may be a critical driver of developmental stress effects on trauma response in adulthood. To test this hypothesis, we induced transient forebrain-specific CRHOE before puberty in double-mutant mice and exposed them to a single traumatic event in adulthood using a well-validated model of PTSD (Adamec et al, 2010; Bakshi et al, 2012). To determine the behavioral sequelae, we assessed PTSD-related symptom clusters, ie, startle reactivity, general and trauma-specific avoidance behaviors. To begin to understand potential mediators of $\mathrm{CRHOE}_{\mathrm{dev}}$ effects, we examined alterations in expression levels of Crhr1-, Crhr2-, and FK506-binding protein 5 gene (Fkbp51), molecules reported to have a role in childhood stress associations with PTSD risk (Binder, 2009; Bradley et al, 2008).

\section{MATERIALS AND METHODS}

\section{Generation of Mice with Inducible Forebrain-Specific CRHOE}

To induce CRHOE in spatio-temporally restricted manner, we used double-mutant mice carrying CamkII $\alpha$ promoterdriven rtta2 transgene (Michalon et al, 2005) and doxycycline (DOX)-regulated tetO promoter fused to the Crh gene (Vicentini et al, 2009) on a C57BL/6J background as previously described (Toth et al, 2014). The Crh transgene was turned on by DOX administration in breeder chow (Harlan Laboratories, Indianapolis, IN) to 'single-mutant' dams from postnatal day 2 for 3 weeks (PND2-PND23). Hence, CRHOE was induced only in double-mutant pups but not in dams. Typical litter sizes were four or five pups, producing one double-mutant male and one double-mutant female on average for testing. The DOX dose administered to the dam (6 mg/g food) induces forebrain-specific expression of $\mathrm{Crh}$ or $\mathrm{Lacz}$ reporter genes in the forebrain as early as PND0, with detectable levels after 4 days, reaching its maximum after 1 week and returning to baseline levels 14 days after DOX treatment is terminated (Michalon et al, 2005; Toth et al, 2014). We and others have previously established that DOX alone (administration between PND2-23) does not affect startle reactivity and avoidance behavior in wild-type mice (Kolber et al, 2010; Toth et al, 2014), therefore control subjects were double-mutant mice without DOX treatment.

\section{Housing Conditions}

All subjects were group housed (3-4 per cage) after weaning (PND28) in a temperature-controlled $\left(21-22^{\circ} \mathrm{C}\right)$ room under a reverse $12 \mathrm{~h}$ light/dark cycle (lights off at 0800 hours). As conducted previously, mice were isolated 1 week before predator stress and housed individually for the remainder of the experiment (Adamec et al, 2010), because pilot studies suggested that isolated mice exhibit stronger predator stress effects owing to lower levels of baseline avoidance behaviors.

\section{Experimental Design}

All testing occurred from 1000 hours to 1800 hours and was conducted in accordance with the Principles of Laboratory Animal Care, National Institutes of Health guidelines, as approved by the University of California San Diego. Before behavioral testing, subjects were brought into an adjacent room under a black cloth $60 \mathrm{~min}$ for habituation. For each test, equipment was cleaned thoroughly with water between testing sessions. One week before predator exposure (13th postnatal week), mice were handled for $1 \mathrm{~min} /$ day and completed a baseline startle assessment. Control and $\mathrm{CRHOE}_{\mathrm{dev}}$ mice were assigned to groups (predator exposure or handling, $N=74,8-11$ per group per sex) after counterbalancing for baseline startle reactivity. Behavioral testing began 7 days after exposure with an open field test (AM) and behavioral pattern monitor (PM). The next day, mice were tested in the light-dark box test (AM) followed by startle assessment (PM). Fourteen and fifteen days after predator exposure, mice were tested in the 'trauma reminder' test. Two separate cohorts of mice with or without predator exposure and DOX administration (4 groups, 5-16 per group per sex, $N=91$ total) were killed for gene expression analysis.

\section{Predator Exposure}

Mice were presented to a cat (Liberty Research, Waverly, NY, USA) in a well-lit room $\left(2.3 \times 1.8 \mathrm{~m}^{2} ; 150-200\right.$ lux $)$ for $10 \mathrm{~min}$. The mouse and cat could freely move within the room. The interaction was recorded and analyzed later by an experimenter blind to treatments. The intensity of stress exposure was quantified by the frequency and duration of the following variables: cat spent near the mouse $(<1 \mathrm{ft})$, sniffing, pawing and mouthing (touching with the mouth without biting) the mouse. None of these behaviors differed

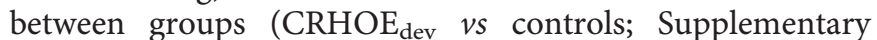
Table 2) and no physical injury occurred. After $10 \mathrm{~min}$ of free interaction, mice were returned to their home cages. Control subjects were exposed to handling for $1 \mathrm{~min}$.

\section{Open Field Test}

Open field activity was assessed in an open arena $\left(40 \times 40 \times 40 \mathrm{~cm}^{3}\right.$; $\left.800 \mathrm{lux}\right)$ for $10 \mathrm{~min}$ and analyzed using Ethovision Tracking Software (Noldus, Leesburg, VA, USA). Total distance moved, entries into and duration of time exploring the center zone $\left(25 \times 25 \mathrm{~cm}^{2}\right)$, and latency of the first entry (mice were placed in the corner) were analyzed.

\section{Open Field Test with Trauma-Reminder}

Open field arena was used to assess avoidance of traumarelated cues: in a cross-over design, either clean mouse bedding or used cat litter (from the cat used for stress exposure; containing urine and fur) was placed into a $50-\mathrm{ml}$ perforated conical tube and affixed to the floor in one corner 
of the arena. The latency of first approach, number of approaches, and time spent within a $3-\mathrm{cm}$ radius zone around the tubes was measured by Ethovision Tracking Software.

\section{Behavioral Pattern Monitor}

Locomotor and exploratory activity was measured in behavioral pattern monitor chambers (San Diego Instruments, San Diego-CA; Risbrough et al, 2006). Each chamber is a clear Plexiglas box containing a $30 \times 60 \mathrm{~cm}^{2}$ holeboard floor. The location of the mouse is obtained from a grid of $12 \times 24$ photobeams $1 \mathrm{~cm}$ above the floor providing a resolution of $1.25 \mathrm{~cm}$ ( +16 beams detecting rears). Mice were placed in the middle of the dark chamber and their activity was assessed by computing total distance moved, number of rears and hole-pokes over $30 \mathrm{~min}$.

\section{Light-Dark Box Test}

The light-dark box consisted of two $20 \times 40 \times 20 \mathrm{~cm}^{3}$ chambers joined by a $6 \times 6 \mathrm{~cm}^{2}$ door. One was well-lit $(950$ lux), whereas the other was covered ( $<5 \operatorname{lux}$ ). Mice were placed in the dark chamber with closed door for $30 \mathrm{~s}$. The test was started by opening the door and lasted $10 \mathrm{~min}$. Latency of the first entry, the number of entries, and time spent in the light chamber were measured by Ethovision Tracking Software.

\section{Acoustic Startle and Prepulse Inhibition (PPI) Assessment}

Startle reactivity was assessed in Plexiglas chambers (San Diego Instruments, San Diego, CA) as previously described (Adamec et al, 2010; Toth et al, 2014). Briefly, 1 week before stress exposure, baseline startle was assessed over 3 consecutive days using Session 1, which presented 10 $105 \mathrm{~dB}$ pulses over $50 \mathrm{~dB}$ background in dark chambers. One week after stress exposure, startle reactivity was re-assessed in two consecutive sessions (Sessions 1 and 2). Session 1 consisted the same parameters as in baseline assessment except that 10 additional pulses (in a pseudorandom order) were presented with houselights on for $2.95 \mathrm{~s}$ before the startle stimulus. This session replicated the acoustic startle session previously described for the mouse predator stress model of PTSD (Adamec et al, 2010). To further assess startle habituation and inhibition as measured by PPI, a second session was presented immediately after the first (Session 2 with $65 \mathrm{~dB}$ background and lights on). This session included five blocks beginning with the delivery of five each of $120 \mathrm{~dB}$ startle pulses (Block1) allowing startle to reach a stable level before specific testing. The second block tested response to $80,90,100,110$, and $120 \mathrm{~dB}$ stimulus intensities. The third block tested PPI using $120 \mathrm{~dB}$ startle pulses with three different prepulse intensities $(69,73$, and $81 \mathrm{~dB})$. The fourth block tested interstimulus interval effects on PPI: $73 \mathrm{~dB}$ prepulses preceding $120 \mathrm{~dB}$ pulses by $25,50,100,200$, or $500 \mathrm{~ms}$. The session ended with five pulses of $120 \mathrm{~dB}$ (Block 5) to assess habituation (from Block1 to Block5). For more details, see Supplementary Material.

\section{Quantitative Real-Time PCR (qRT-PCR)}

We assessed expression levels of four CRH-related genes in order to identify CRH-induced changes, which may mediate increased vulnerability to traumatic stress. We assessed Crhr1 and Crhr2 expression in three brain regions: amygdala, bed nucleus of stria terminalis (BNST), and lateral septum, which are areas of relatively high expression for at least one of these genes (Van Pett et al, 2000). We also assessed Fkbp51 in the hippocampus and neocortex, areas of moderate to high expression for these genes (Scharf et al, 2011). Briefly, male/female DOX-treated/untreated and handled/predator stressed double-mutant mice were killed 7 days after predator stress exposure, regions of interest were dissected on ice-cold platform immediately after brain extraction and were placed in $1.5 \mathrm{ml}$ tubes containing $500 \mu \mathrm{l}$ of RNA Later (Life Technologies, Carlsbad, CA). Taqman qRT-PCR was run following RNA extraction and cDNA synthesis using commercially available kits. For more details, see Supplementary Material. For each sample, expression of each gene of interest was compared with the housekeeping gene Gapdh. Fold differences vs control (no DOX) were calculated for each sex. Because of technical reasons sample sizes varied across regions.

\section{Statistical Analysis}

Behavioral and qRT-PCR data were analyzed using factorial ANOVA tests with sex, stress, and $\mathrm{CRHOE}_{\mathrm{dev}}$ as betweensubject factors for all tests and in the case of startle habituation block or intensity was included as a withinsubject factor (Systat, Chicago, IL, USA). In the case of main effects or interactions with sex, data were then analyzed separately within each sex. If groups differed in activity measures, an additional covariate analysis was also presented to control for non-specific activity effects. qRT-PCR data were also analyzed using covariance analysis and variance estimation/precision model to test if there was difference between cohorts: significant changes are shown only if latter indicated no cohort-effect. Data were logarithmic or square-root transformed where necessary. When appropriate, Fisher's LSD post hoc comparisons were also conducted. However, given that multiple tests were used to measure a similar behavioral construct (avoidance) with relatively lenient statistical cutoffs, we also created a composite avoidance score (average $z$-score of time in the aversive area in each avoidance test: center of open field; light compartment of light-dark box; near the tube filled with cat litter), which is common in clinical research when multiple measures of a similar construct are conducted (for more details, see Supplementary Material). This approach enables a more accurate determination of consistent changes in avoidance behavior across multiple tests, calculates overall effect size, and reduces family-wise error due to multiple testing.

\section{RESULTS}

\section{Avoidance in the Open Field}

Predator stress exposure increased avoidance of the center (frequency, duration and latency measures: $\mathrm{F}_{\text {stress }}(1,66)$ $>8.08, p<0.01$; Figure 1; Tables 1 and 2) and decreased 

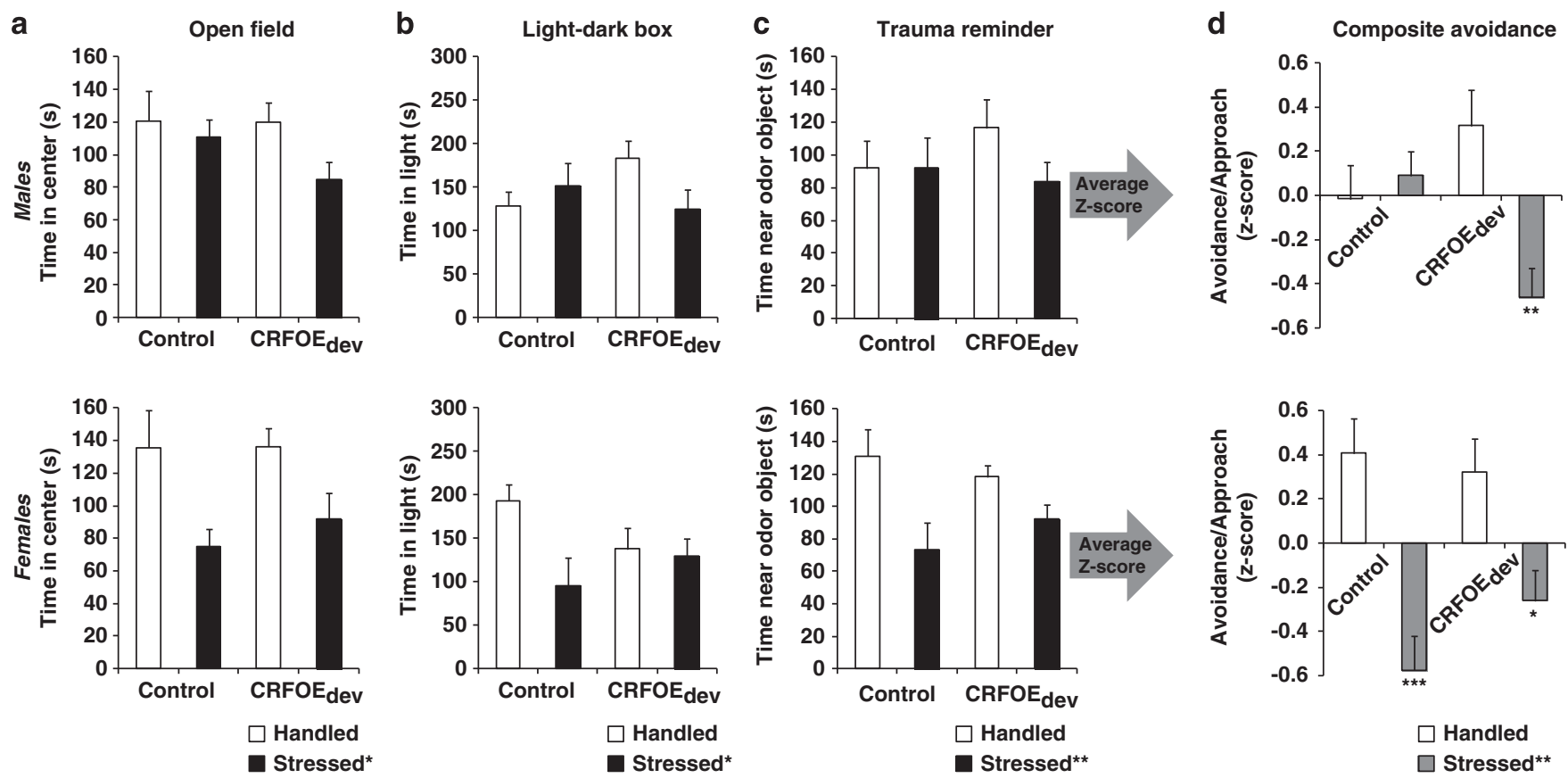

Figure I Avoidance behavior in open field (a), light-dark box (b), and trauma reminder (c) tests, and their composite avoidance score (d) indexed by average $z$-scores of the three tests. All graphs indicate time spent in the aversive arenas (ie, center of the open field, light compartment of the light-dark box, and zone around the tube filled with cat litter). Lower/negative scores indicate increased avoidance of the aversive zone. Upper and lower panels show data from males and females, respectively. Data are presented as mean \pm SEM. Asterisks in legends indicate significant main effect of stress $(* p<0.05$; $* * P<0.0$; ***** $p<0.00$ I; indicated by three-way ANOVA); whereas asterisks above bars indicate significant interactions followed by post hoc comparisons vs handled group with the same CRF background. $C R H O E_{d e v}$, transitional $\mathrm{CRH}$ overexpression before puberty.

exploration (total distance moved; $\mathrm{F}_{\text {stress }}(1,66)=13.25$, $p<0.001$; Tables 1 and 2). Reduced center exploration was independent of overall locomotor activity changes as center duration and latency to enter the center remained significantly lower in the stressed groups when total distance moved was considered as a covariate $\left(\mathrm{F}_{\text {stress }}(1,65)>5.68\right.$, $p<0.05)$. The impact of stress on latency to enter the center was significantly modulated by sex and $\mathrm{CRHOE}_{\mathrm{dev}}$ exposure $\left(\mathrm{F}_{\text {sex }} \times\right.$ stress $\left.\times \operatorname{CRHOE}(1,66)=5.23, \quad p<0.05\right)$, with increased latency to enter reduced in male mice exposed to both stress and $\mathrm{CRHOE}_{\mathrm{dev}}$ compared with all other male groups $(0.017<p<0.085$; Table 1$)$. Females exposed to predator stress showed significant reductions in center duration and number of entries regardless of $\mathrm{CRHOE}_{\mathrm{dev}}$ exposure (Figure 1 and Table 2).

\section{Avoidance in the Light-Dark Box}

Mice exposed to predator stress exhibited increased avoidance of the light chamber (frequency: $\mathrm{F}_{\text {stress }}(1,66)=5.16, p<0.05$; duration: $\mathrm{F}_{\text {stress }}(1,66)=4.87, p<0.05$; latency: $\mathrm{F}_{\text {stress }}(1,66)=$ 2.21, ns; Tables 1 and 2) in a sex- and $\mathrm{CRHOE}_{\mathrm{dev}^{-} \text {-dependent }}$ manner (frequency, duration, and latency measures: $\mathrm{F}_{\text {sex } \times \text { stress }} \times$ CRHOE $(1,66)=7.15, p<0.01 ; \mathrm{F}_{\text {sex } \times \text { stress } \times \text { CRHOE }}(1,66)=$ $5.62, \quad p<0.05 ; \quad \mathrm{F}_{\text {sex } \times \text { stress } \times \operatorname{CRHOE}}(1,66)=2.91, \quad p=0.092$, respectively). Male mice exposed to both $\mathrm{CRHOE}_{\mathrm{dev}}$ and stress exhibited higher avoidance (frequency and duration: $p<0.05$ and $p=0.063$, respectively compared with handled $\mathrm{CRHOE}_{\mathrm{dev}}$; Figure 1 and Table 1). In contrast, predator stress increased avoidance of the light chamber in females regardless of $\mathrm{CRHOE}_{\mathrm{dev}}$ exposure (Figure 1 and Table 2). $\mathrm{CRHOE}_{\mathrm{dev}}$ females also exhibited a trend for increased avoidance in non-stressed groups (duration: $\mathrm{F}_{\text {stress } \times \mathrm{CRHOE}}(1,32)=3.49$, $p=0.071$, post hoc: $p=0.098$; Table 2 ) as described previously (Toth et al, 2014).

\section{Avoidance of Trauma-Associated Cue}

Overall, predator stress increased avoidance of the trauma reminder as indexed by decreased exploration of the tube containing cat litter (frequency: $\mathrm{F}_{\text {stress }}(1,66)=4.38, p<0.05$; duration: $\mathrm{F}_{\text {stress }}(1,66)=7.78, p<0.01$; latency: $\mathrm{F}_{\text {stress }}(1,66)$ $<1, \mathrm{~ns})$, which was independent of sex and $\mathrm{CRHOE}_{\mathrm{dev}}$. Exploration of the neutral tube was not affected by predator stress (all measures: $\mathrm{F}_{\text {stress }}(1,66)<2.63$, ns). $\mathrm{CRHOE}_{\mathrm{dev}}$ alone had no effect on avoidance of either tube (duration and frequency: $\left.\mathrm{F}_{\mathrm{CRHOE}}(1,66)<1, \mathrm{~ns}\right)$, but did increase latency to explore the litter tube as well as increased total distance moved $\left(\mathrm{F}_{\mathrm{CRHOE}}(1,66)>4.40 ; p s<0.05\right)$.

\section{Avoidance Across Testing Paradigms: Combined Avoidance Score}

To better quantify the 'overall' avoidance profile of mice exposed to $\mathrm{CRHOE}_{\mathrm{dev}}$ and predator stress, we utilized a composite score approach on the combined $z$-scores of the avoidance tests. This approach highlights where an individual falls in the overall distribution of each test most consistently. The average $z$-score of three avoidance tests confirmed the highly significant effect of stress on avoidance 
Table I Avoidance Behavior in Males Exhibited in the Open Field, Light-Dark Box, and Modified Open Field with Trauma-Reminder

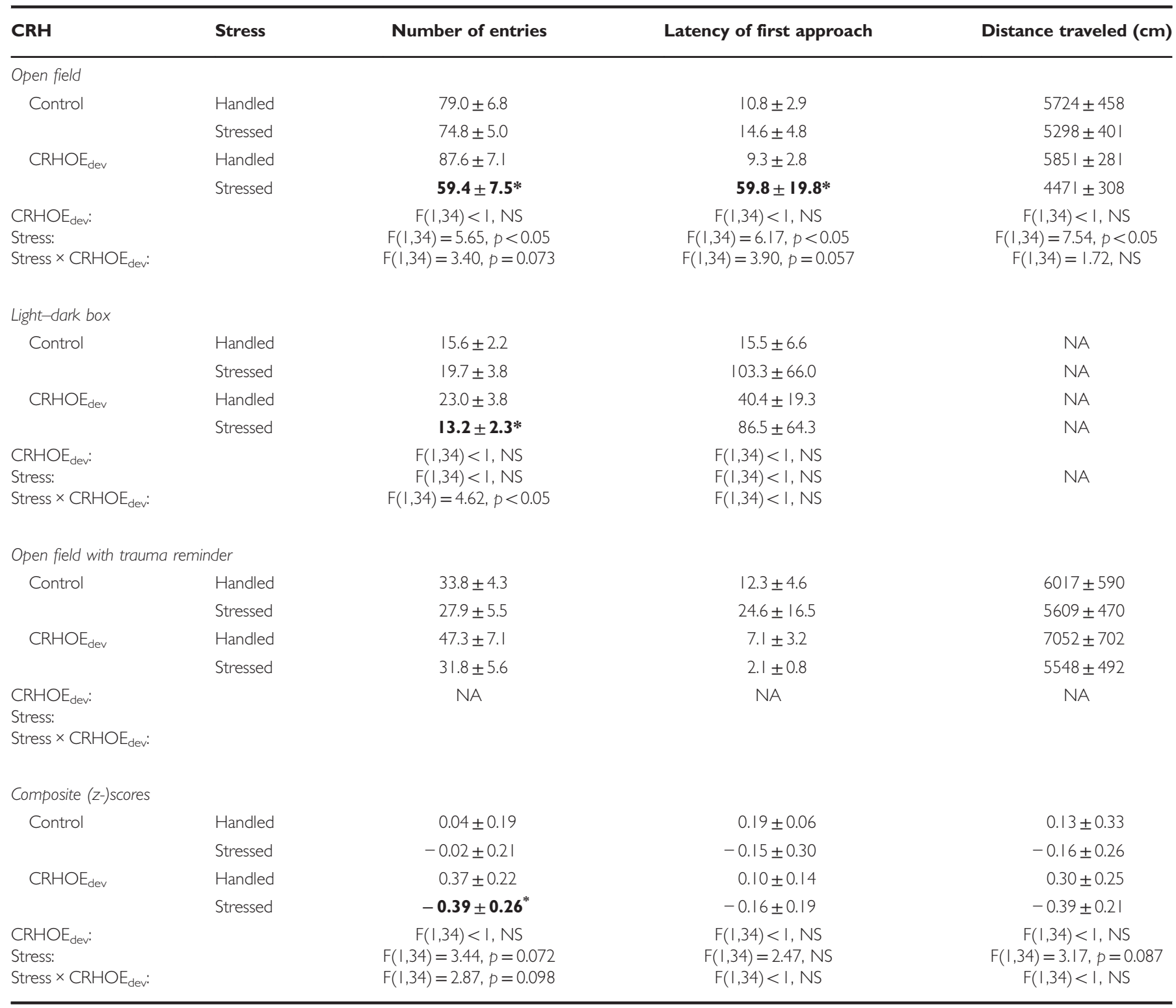

Data (presented as mean \pm SEM) show the number of entries into the aversive arena (ie, center, light compartment, and zone around the tube filled with cat litter), the latency of the first approach to the aversive arena, and total distance traveled. Distance traveled is not available in the light-dark box as the dark compartment is covered. * $p<0.05$ post hoc test compared with handled controls with the same $\mathrm{CRH}$ condition (indicated in bold); $C R H O E_{\text {dev }}$ : transitional $\mathrm{CRH}$ overexpression before puberty. Note: only overall effects of predator stress were detected in the trauma reminder test, thus separate analyses across sexes are not presented, see Results.

(all measures: $\mathrm{F}_{\text {stress }}(1,66)>11.08,0.001<p<0.002$; duration shown in Figure 1), which showed strong interaction with $\mathrm{CRHOE}_{\mathrm{dev}}$ in a sex-dependent manner (frequency and duration: $\left.\mathrm{F}_{\text {sex } \times \text { stress } \times \text { CRHOE }}(1,66)>7.82,0.002<p<0.007\right)$. Post hoc analysis confirmed the general pattern of findings in the individual tests: with predator stress increasing avoidance only in male mice previously exposed to $\mathrm{CRHOE}_{\mathrm{dev}}$ (Figure 1; Tables 1 and 2; effect of stress on frequency and duration in $\mathrm{CRHOE}_{\mathrm{dev}}$ groups: $p<0.05$ and $p<0.01$, respectively; no effect of stress in male non$\mathrm{CRHOE}_{\mathrm{dev}}$ mice). However, there was a trend for increased approach in handled $\mathrm{CRHOE}_{\mathrm{dev}}$ male mice compared to handled controls $(p=0.076)$. Consistently with individual tests, post hoc analysis in females showed a robust effect of predator stress on avoidance in both $\mathrm{CRHOE}_{\mathrm{dev}}$ and non$\mathrm{CRHOE}_{\mathrm{dev}}$ groups $(p<0.05$ and $p<0.001$, respectively; Figure 1 and Table 2). Factor loading-weighted $z$-scores showed highly similar results (duration in open field, ligh-dark box and odor test loadings: $0.73,0.68$, and 0.49 , respectively; $\quad \mathrm{F}_{\text {sex } \times \text { stress } \times \text { CRHOE }}(1,66)=10.19, \quad p<0.01$; post hoc: handled $v s$ stressed $\left.\mathrm{CRHOE}_{\mathrm{dev}} p<0.01\right)$.

\section{Locomotor and Exploratory Activity}

$\mathrm{CRHOE}_{\mathrm{dev}}$ increased the total distance moved in the behavioral pattern monitor but did not affect the number of rears and hole-pokes $\left(\mathrm{F}_{\mathrm{CRHOE}}(1,66)=5.50, p<0.05\right.$; $\mathrm{F}_{\mathrm{CRHOE}}(1,66)<1$, ns; $\mathrm{F}_{\mathrm{CRHOE}}(1,66)<1$, ns, respectively). 
Table 2 Avoidance Behavior in Females Exhibited in the Open Field, Light-Dark Box, and Modified Open Field with Trauma-Reminder

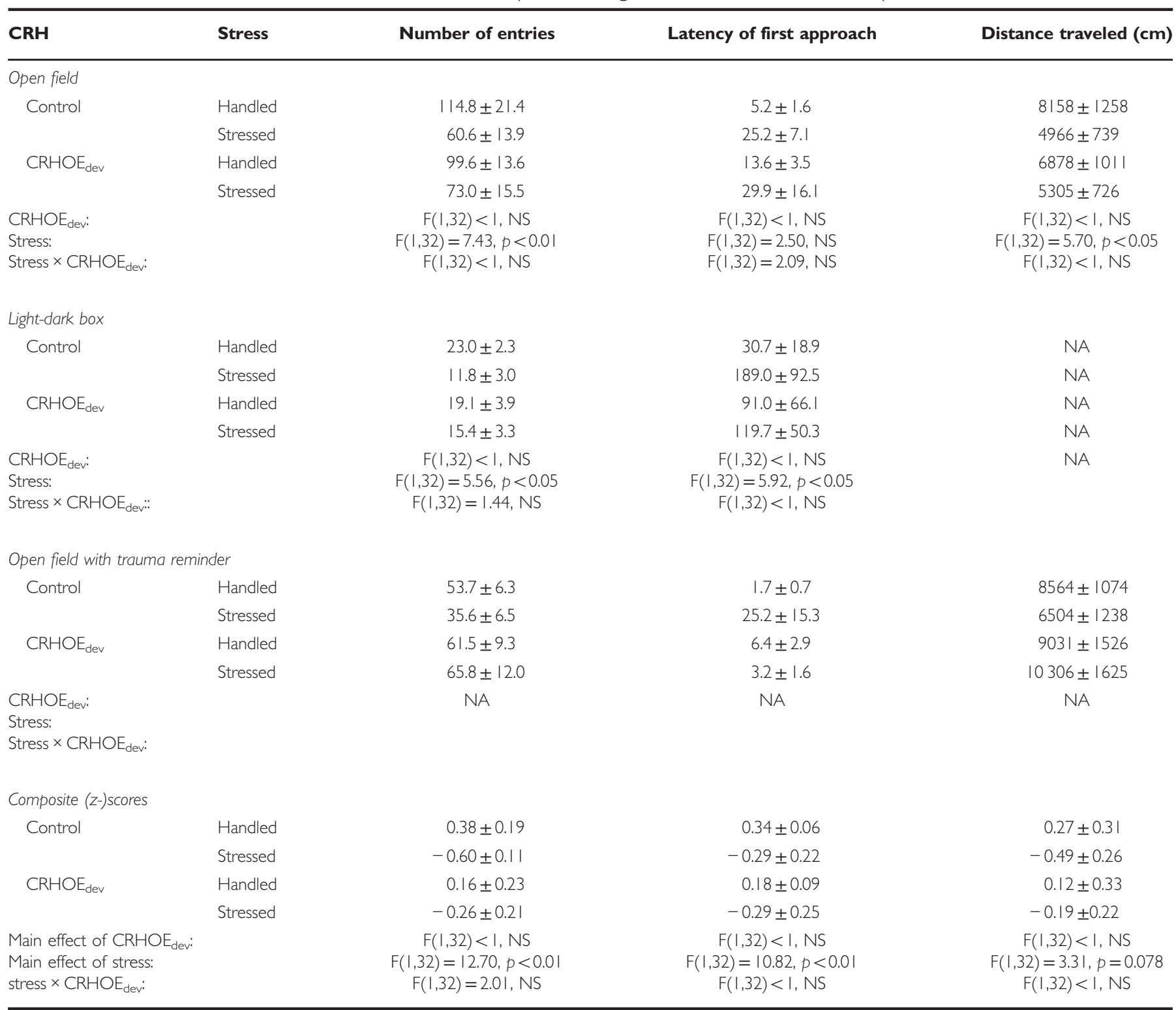

Data (presented as mean \pm SEM) show the number of entries into the aversive arena (ie, center, light compartment, and zone around the tube filled with cat litter), and the latency of the first approach and total distance traveled. Distance traveled is not available in the light-dark box as the dark compartment is covered. * $p<0.05$ compared with handled controls with the same CRH condition (post hoc); CRHOE devi transitional CRH overexpression before puberty. Note: only overall effects of predator stress were detected in the trauma reminder test, thus separate analyses across sexes are not presented, see Results.

Predator stress did not alter total distance moved or number of rears $\left(\mathrm{F}_{\text {stress }}(1,66)<1\right.$, ns) but decreased the number of hole-pokes $\left(\mathrm{F}_{\text {stress }}(1,66)=8.20, \quad p<0.01 ; \quad\right.$ Supplementary Table 1).

\section{Startle Reactivity and PPI}

Both before and following stress exposure, $\mathrm{CRHOE}_{\mathrm{dev}}$ exposed mice showed higher startle magnitude regardless of $\operatorname{sex}\left(\mathrm{F}_{\mathrm{CRHOE}}(1,66)=4.61, p<0.05 ; \mathrm{F}_{\mathrm{CRHOE}}(1,66)=9.52\right.$, $p<0.01$, respectively; Figure 2a and Supplementary Figure 1, $\mathrm{F}_{\mathrm{CRHOE}} \times$ Stress $\times$ Sex $(1,66)<1$, ns). $\mathrm{CRHOE}_{\mathrm{dev}}$ also robustly reduced startle habituation independently of sex or stress exposure $\left(\mathrm{F}_{\text {block } \times \text { CRHOE }}(4,264)=2.72, p<0.05\right.$; Post hoc main effect of block $p<0.05$ in controls, $p>0.3$ in $\mathrm{CRHOE}_{\mathrm{dev}}$ mice; Figure 2b). Similarly, PPI was significantly reduced by CRHOE $_{\text {dev }}\left(\mathrm{F}_{\mathrm{CRHOE}}(1,66)=9.43, p<0.01\right)$, although this effect appeared to be stronger in males (Figure 2c). When startle magnitude was added as a covariate, the $\mathrm{CRHOE}_{\mathrm{dev}}$ effect on PPI remained significant $\left(F_{\text {stress }}(1,65)=15.84\right.$, $p<0.001)$, suggesting the PPI effect was independent of effects on startle. Predator stress alone had no effect on any startle measures $\left(\mathrm{F}_{\text {stress }}<2.08\right.$, ns; $\mathrm{F}_{\text {stress } \times \mathrm{CRHOE}}<1.22$, ns; Figure 2).

\section{Gene Expression Changes Induced by $\mathrm{CRHOE}_{\mathrm{dev}}$}

Crhr1 expression was slightly reduced in the amygdala in stressed mice regardless of sex or $\mathrm{CRHOE}_{\mathrm{dev}}$ exposure (Figure 3a; $\left.\mathrm{F}_{\text {stress }}(1,86)=3.14, p=0.080\right)$. Crhr1 expression 

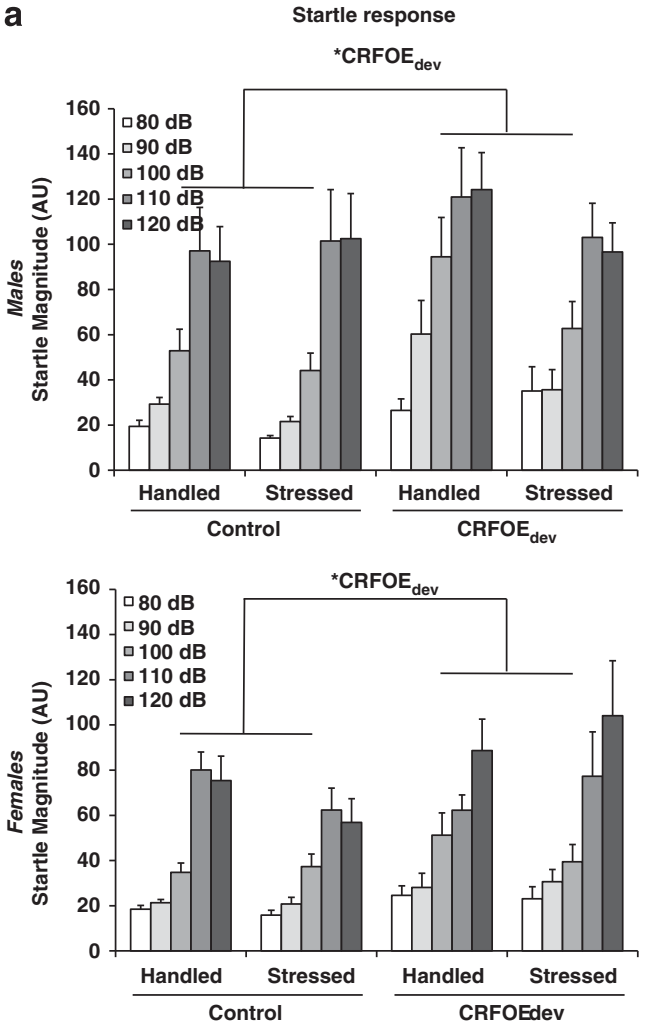

b
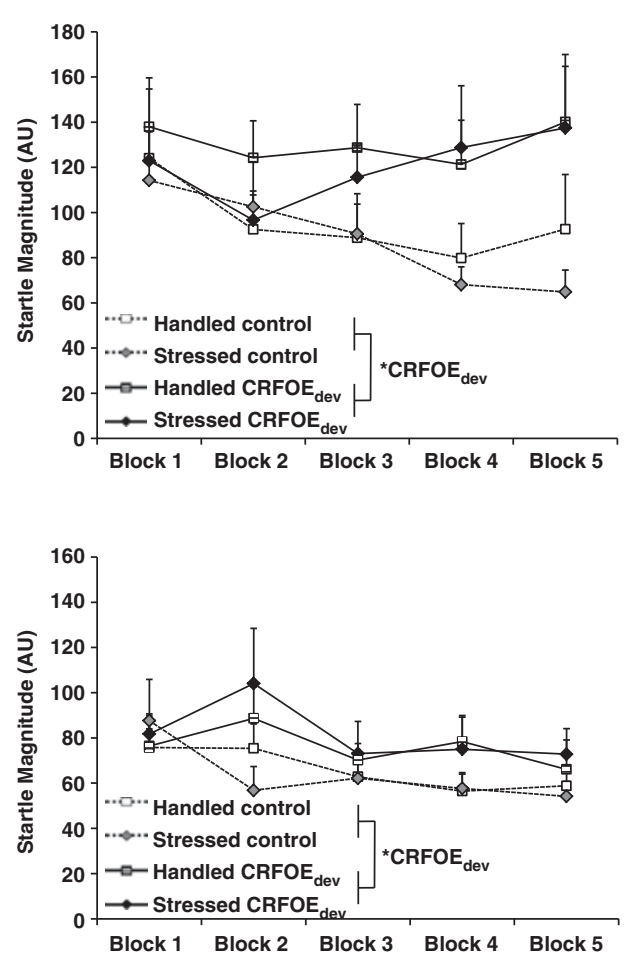

C
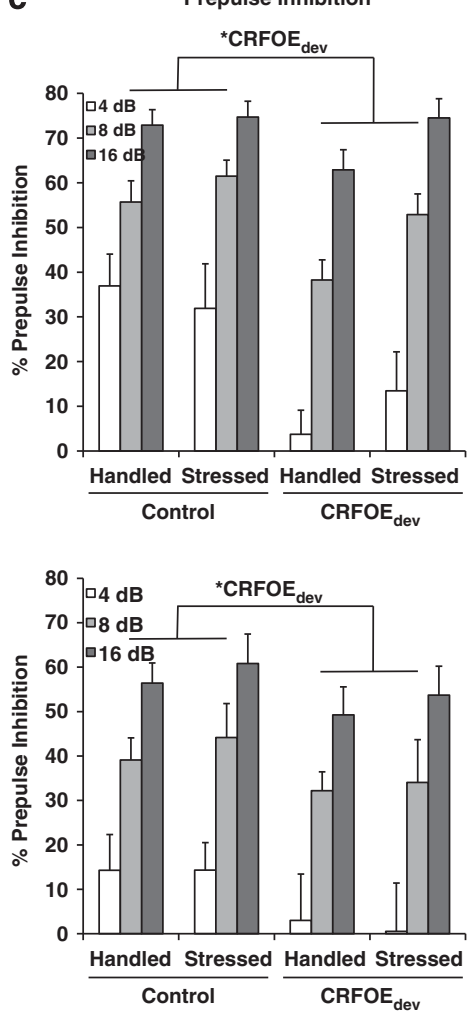

Figure 2 The magnitude (a), habituation (b), and prepulse inhibition (c) of the startle response. Upper and lower panels show data from males and females, respectively. Data are presented as mean $\pm \mathrm{SEM}$. Asterisks indicate significant $(* p<0.05)$ main effect of $\mathrm{CRHOE}_{\text {dev }}$ (or in the case of habituation, block $\times \mathrm{CRHOE}_{\text {dev }}$ interaction; indicated by repeated measure ANOVA). $C R H O E_{\text {dev }}$, transitional $\mathrm{CRH}$ overexpression before puberty.

a
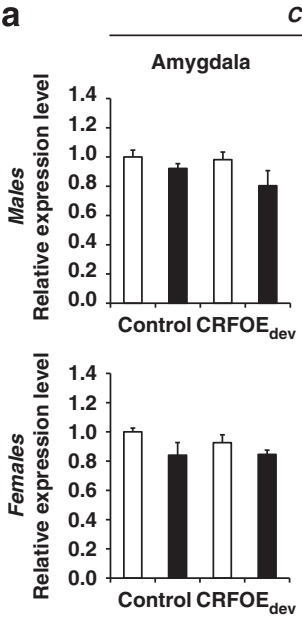

Crhr1
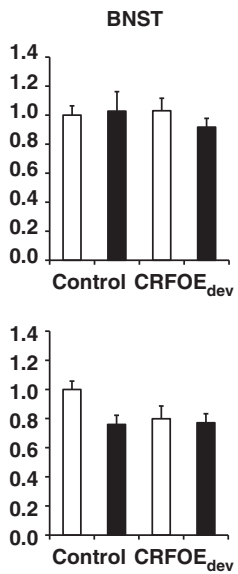

b
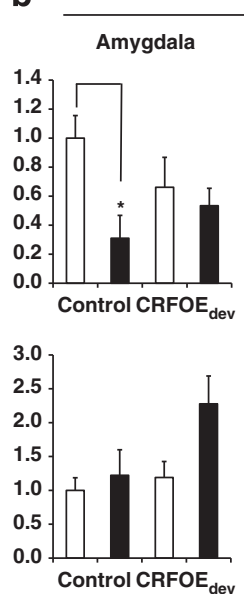

Crhr2
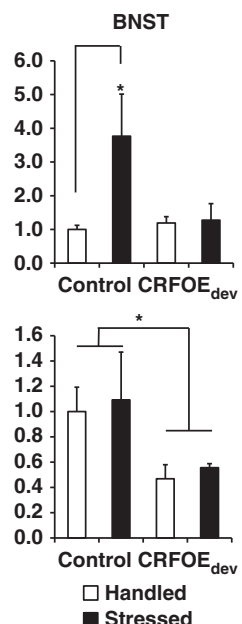

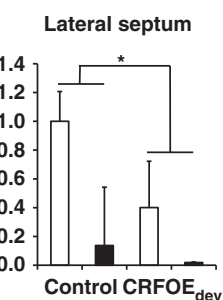

C
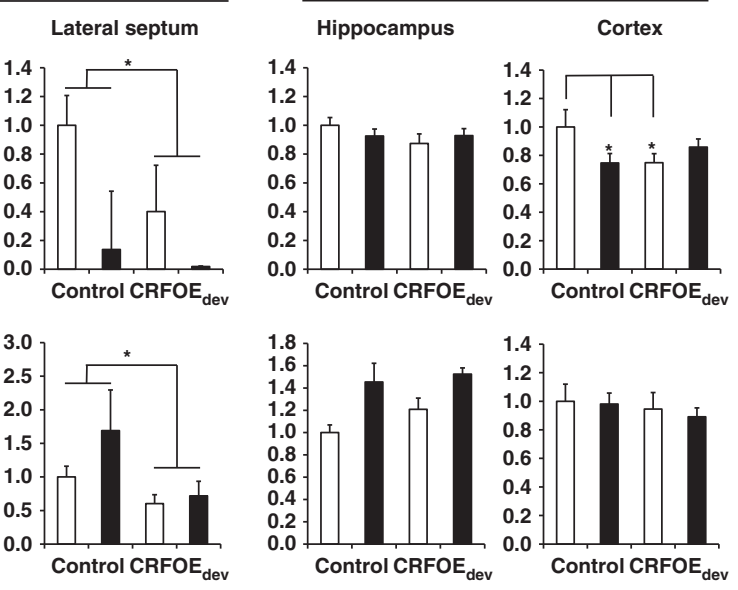

Figure 3 Long-term expression changes of Crhrl (a), Crhr2 (b), and Fkbp5I (c) in regions of interest. Data are presented as mean \pm SEM of fold changes compared with handled 'no DOX' controls (normalized to housekeeping gene Gapdh). * $p<0.05$; *** $p$ 0.0 I main effect of CRHOE dev (Crhr2-Lateral Septum), or significant post hoc comparison to respective groups as indicated by lines. For full description of all main effects and trends, see Results. BNST, bed nucleus of stria terminalis; $C R H O E_{d e v}$, transitional CRH overexpression before puberty; Crhrl/Crhr2, CRH receptor type I and type 2; Fkbp5 I, FK506-binding protein of the glucocorticoid receptor.

was also slightly decreased in BNST in female mice exposed to stress compared with handled controls (Figure 3a; $\mathrm{F}_{\text {sex }}(1,85)=4.39, p<0.05 ; \mathrm{F}_{\text {stress }} \times \mathrm{CRHOE}(1,40)=4.60, p<0.05$; Tukey's post hoc test $p=0.098$ handled controls $v s$ stressed controls; Figure 3). The impact of stress on Crhr2 expression depended on sex and $\mathrm{CRHOE}_{\text {dev }}$ exposure. In the amygdala, $\mathrm{Crhr} 2$ was reduced in stressed males, and marginally increased in females exposed to both $\mathrm{CRHOE}_{\mathrm{dev}}$ and stress 
$\left(\mathrm{F}_{\text {sex }}(1,79)=15.66, \quad p<0.001 ; \quad\right.$ males: $\quad \mathrm{F}_{\text {stress }}(1,32)=5.17$; $p<0.05$; females: $\mathrm{F}_{\text {stress } \times \text { CRHOE }}(1,40)=3.35 ; \quad p=0.074$; Figure 3). In the BNST, stress increased Crhr2 in nonCRHOE exposed males only $\left(\mathrm{F}_{\text {sex }}(1,76)=8.01, p<0.01\right.$; males: $\mathrm{F}_{\text {stress } \times \text { CRHOE }}(1,35)=14.33, \quad p<0.001$; post hoc: $p<0.001$ compared to all other groups), whereas stress had no effect on Crhr2 levels in females. $\mathrm{CRHOE}_{\mathrm{dev}}$ exposure, however, significantly reduced Crhr2 levels in females regardless of stress $\left(\mathrm{F}_{\mathrm{CRHOE}}(1,36)=5.69, p<0.05\right)$. In the lateral septum, Crhr2 was significantly reduced by $\mathrm{CRHOE}_{\mathrm{dev}}$ in both sexes $\left(\mathrm{F}_{\mathrm{CRHOE}}(1,74)=7.81, p<0.05\right.$; Figure 3) with no significant effects of stress. Stress-induced alterations of $F k b p 51$ expression was also modulated by sex and $\mathrm{CRHOE}_{\mathrm{dev}}$. In males, predator exposure or $\mathrm{CRHOE}_{\mathrm{dev}}$ reduced Fkbp51 expression compared with handled controls $\left(\mathrm{F}_{\text {stress } \times \text { CRHOE }}(1,16)=5.38, \quad p<0.05 ;\right.$ post hoc: $p<0.05$ handled $\mathrm{CRHOE}_{\mathrm{dev}}$ and stressed controls $v s$ handled controls; Figure 3). Stress marginally increased hippocampal Fkbp51 expression in females $\left(\mathrm{F}_{\text {sex }}(1,86)=17.39, p<0.001\right.$; females: $\left.\mathrm{F}_{\text {stress }}(1,41)=3.12, p=0.084\right)$.

\section{DISCUSSION}

Here we show that a single 'traumatic stress' event induced significant avoidance behavior that was modulated by forebrain-specific CRHOE during early-life in a sex-dependent manner. In female mice, trauma-induced avoidance was pronounced, but was not significantly influenced by early-life CRHOE. In contrast, male mice exhibited significant trauma-induced avoidance only when they had been exposed to early-life CRHOE. Hence, in males, forebrain $\mathrm{CRH}$ signaling during development may be sufficient to induce the 'double hit' phenomenon, in which early-life stress interacts with adult trauma to induce PTSD-like symptoms. Moreover, early-life CRHOE led to lasting increases of arousal indexed by startle reactivity in both sexes. Sex-specific alterations of Fkbp51 and Crhr2 expression in response to stress and/or $\mathrm{CRHOE}_{\mathrm{dev}}$ suggest that consequences of excess $\mathrm{CRH}$ signaling during development on stress pathways are dependent on sex and may explain the sexually dimorphic behavioral outcomes.

That predator stress significantly impacted avoidance in control females, but not in control males, suggests that this model may be predictive for mechanisms related to clinical findings reporting higher risk for women to develop stress disorders, including PTSD (Kessler et al, 2010; Koenen and Widom, 2009; Tolin and Foa, 2006). Moreover, it was only with the additional manipulation of CRHOE during early-life that males exhibited a response to predator stress. Accumulating evidence indicates that $\mathrm{CRH}$-related mechanisms contribute to sex differences in stress reactivity and anxiety. For instance, sexes differ in $\mathrm{CRH}$ receptor and Fkbp5 expression during early development, particularly following early-life stress (Bourke et al, 2013; Weathington et al, 2014). Moreover, enhanced $\mathrm{CRH}$ neurotransmission during early-life induces sex-specific alterations in monoaminergic systems (Curtis et al, 2006; Howerton et al, 2014; McEuen et al, 2009). The sex-dependent effects of predator stress in the present study may also be due to the reduced ability of females to desensitize CRH receptors (Bangasser et al, 2010). In the present study, males that were not exposed to
$\mathrm{CRHOE}_{\mathrm{dev}}$ showed robust expression changes in Crhr2 in response to predator stress, although the direction of change was different across brain regions in keeping with the differential effects of CRHR2 signaling on behavior across these regions (Hauger et al, 2009). Conversely, males exposed to $\mathrm{CRHOE}_{\mathrm{dev}}$ and female mice show no significant changes in Crhr2 expression in response to stress. For example, males exhibited a $>3$-fold increase in Crhr2 in BNST in response to stress, whereas females and males exposed to $\mathrm{CRHOE}_{\mathrm{dev}}$ showed no significant change in response to stress (Figure 3 ). These findings suggest that the Crhr2 expression changes observed in males is a candidate mechanism for resiliency against enduring effects of trauma, and that early-life exposure to $\mathrm{CRH}$ could attenuate this adaptive response. Supporting the former suggestion, lentivirus-mediated increases in Crhr2 expression in the BNST reduce PTSD-like susceptibility in male rats (Elharrar et al, 2013) but see Lebow et al (2012). 'PTSD-responsive' mice also show less overall transcriptional change in response to stress compared with 'PTSD-resilient' mice (Lebow et al, 2012), suggesting that enduring anxiety after trauma may be in part related to attenuated adaptation of stress systems. The present study also observed that males, but not females, exposed to $\mathrm{CRHOE}_{\mathrm{dev}}$ or stress exhibited reduced cortical expression of $F k b p 51$, a protein that curbs excess glucocorticoid signaling and modulates the association between early-life stress and PTSD (Binder, 2009; Yehuda et al, 2009; Sarapas et al, 2011; Yehuda et al, 2009). Recent prospective studies indicate that reduced Fkbp5 expression before trauma is a risk factor for the development of PTSD (van Zuiden et al, 2012). Hence, reduced Fkbp51 expression found in males is another candidate mechanism for $\mathrm{CRHOE}_{\mathrm{dev}}$ effects on anxiety. These data must be interpreted with caution, however, as specific manipulation of Fkbp51 and Crhr2 expression is required to confirm any causal relationship between expression changes and PTSD-like phenotypes observed. Overall, the differential pattern of Crhr2 vs Fkbp51 expression changes in female and male mice supports the hypothesis that sex significantly modulates adaptive responses in $\mathrm{CRH}$ signaling during development (Bale et al, 2002; Bangasser et al, 2010).

Our present findings also support the conclusion that early-life CRH signaling modulates development of startle circuitry. These data are consistent with our and others' previous reports showing reduced PPI and habituation following developmental or lifetime CRHOE (Dirks et al, 2002; Groenink et al, 2008; Toth et al, 2014). Pharmacological and genetic manipulation studies reported increased startle and reduced PPI following CRHR1 receptor hypersignaling, whereas CRHR2 receptor stimulation increased PPI (Risbrough et al, 2003, 2004). Given that CRHR2 receptor stimulation increases PPI, CRHOE $\mathrm{dev}$-induced deficits in PPI may be due to reductions in expression of $\mathrm{Crhr} 2$ in the lateral septum observed across sexes (Figure 3). In the lateral septum, Crhr2 receptor expressing neurons mediate anxiogenic effects (Anthony et al, 2014), however, the effects of septal CRHR2 signaling on sensorimotor gating are unknown. In the present study, predator stress had no further impact on startle, despite previous reports that predator stress increases startle magnitude (Adamec et al, 2010). These data indicate that the predator stress model may be most consistent in modeling the avoidance-like components 
of PTSD rather than full PTSD-syndrome. It is important to consider that reports of increased baseline startle, reduced habituation, and PPI are inconsistent in PTSD patients (Acheson et al, 2014). Indeed, PTSD is more robustly associated with increased startle reactivity in response to specific threat, not under baseline conditions as was assessed here (Grillon and Baas, 2003; Orr et al, 2002; Acheson et al, 2014).

Taken together, these data support the suggestion that early-life $\mathrm{CRH}$ hyper-signaling in the forebrain is sufficient to increase enduring effects of adulthood trauma in males. $\mathrm{CRH}$ may exert these effects via altering signaling (CRHR2) or the glucocorticoid feedback (Fkbp5) during development. Importantly, early-life $\mathrm{CRH}$ hyper-signaling results in structural deficits (Chen et al, 2004), anxiogenic, and despair-like effects, which cannot be reproduced by adultonset CRHOE (Kolber et al, 2010; Toth et al, 2014). Here we show that these early-life stress effects are markedly modulated by sex, potentially via sex-specific compensatory mechanisms in response to $\mathrm{CRH}$ hyper-signaling. Accumulating evidence supports the importance of sex differences in the neurobiological consequences of stress pathway activation during development and response to trauma (De Bellis and Keshavan, 2003; Everaerd et al, 2012).

\section{FUNDING AND DISCLOSURE}

This work was performed with the support of the Genomics and Sequencing Core at the UC San Diego Center for AIDS Research (P30 AI036214), the VA San Diego Healthcare System, and the Veterans Medical Research Foundation. These studies were supported by Grants NIMH R074697 and a VA Merit Award for Dr Risbrough, T32 MH18399 for Dr Flandreau, and the San Diego Veterans Administration Center of Excellence for Stress and Mental Health. Drs Toth, Flandreau, and Mansuy have no potential financial conflicts to report. Dr Risbrough also had research support from Sunovion, Janssen, Pfizer, and Omeros. Dr Merlo Pich was a full-time employee of GlaxoSmithKline SPA, Italy, until December 2011; and since 2012, he has been a full-time employee of $\mathrm{F}$ Hoffmann-La Roche, Basel. In the past 3 years, Dr Geyer has received consulting compensation from Abbott, Acadia, Addex, Cerca, Dart, Lundbeck/Otsuka, Merck, Neurocrine, Omeros, Takeda, and Teva, and holds an equity interest in San Diego Instruments. Dr Geyer also has research grant support from the NIDA, NIMH, and the US Veterans Administration VISN 22 Mental Illness Research, Education, and Clinical Center.

\section{ACKNOWLEDGMENTS}

We are grateful to Dr Robert Adamec for his advice in establishing the predator stress model of PTSD, and dedicate this manuscript to his memory. We thank Maya Gross for her technical assistance.

\section{REFERENCES}

Acheson D, Geyer MA, Risbrough VB (2014). Psychophysiology in the study of psychological trauma: where are we now and where do we need to be? Curr Topics Behav Neurosci 21: 157-183.
Adamec R, Fougere D, Risbrough V (2010). CRF receptor blockade prevents initiation and consolidation of stress effects on affect in the predator stress model of PTSD. Int J Neuropsychopharmacol 13: 747-757.

Anthony TE, Dee N, Bernard A, Lerchner W, Heintz N, Anderson DJ (2014). Control of stress-induced persistent anxiety by an extraamygdala septohypothalamic circuit. Cell 156: 522-536.

Bakshi VP, Alsene KM, Roseboom PH, Connors EE (2012). Enduring sensorimotor gating abnormalities following predator exposure or corticotropin-releasing factor in rats: a model for PTSD-like information-processing deficits? Neuropharmacology 62: 737-748.

Bale TL, Picetti R, Contarino A, Koob GF, Vale WW, Lee KF (2002). Mice deficient for both corticotropin-releasing factor receptor 1 (CRFR1) and CRFR2 have an impaired stress response and display sexually dichotomous anxiety-like behavior. J Neurosci 22: 193-199.

Bangasser DA, Curtis A, Reyes BA, Bethea TT, Parastatidis I, Ischiropoulos $\mathrm{H}$ et al (2010). Sex differences in corticotropinreleasing factor receptor signaling and trafficking: potential role in female vulnerability to stress-related psychopathology. Mol Psychiatry 15: 877, 896-904.

Binder EB (2009). The role of FKBP5, a co-chaperone of the glucocorticoid receptor in the pathogenesis and therapy of affective and anxiety disorders. Psychoneuroendocrinology 34 (Suppl 1): S186-S195.

Bourke CH, Raees MQ, Malviya S, Bradburn CA, Binder EB, Neigh GN (2013). Glucocorticoid sensitizers Bag1 and Ppid are regulated by adolescent stress in a sex-dependent manner. Psychoneuroendocrinology 38: 84-93.

Bradley RG, Binder EB, Epstein MP, Tang Y, Nair HP, Liu W et al (2008). Influence of child abuse on adult depression: moderation by the corticotropin-releasing hormone receptor gene. Arch Gen Psychiatry 65: 190-200.

Bremner JD, Licinio J, Darnell A, Krystal JH, Owens MJ, Southwick SM et al (1997). Elevated CSF corticotropin-releasing factor concentrations in posttraumatic stress disorder. $A m \mathrm{~J}$ Psychiatry 154: 624-629.

Carpenter LL, Tyrka AR, McDougle CJ, Malison RT, Owens MJ, Nemeroff $\mathrm{CB}$ et al (2004). Cerebrospinal fluid corticotropinreleasing factor and perceived early-life stress in depressed patients and healthy control subjects. Neuropsychopharmacology 29: 777-784.

Chen Y, Bender RA, Brunson KL, Pomper JK, Grigoriadis DE, Wurst W et al (2004). Modulation of dendritic differentiation by corticotropin-releasing factor in the developing hippocampus. Proc Natl Acad Sci USA 101: 15782-15787.

Cicchetti D, Rogosch FA, Oshri A (2011). Interactive effects of corticotropin releasing hormone receptor 1, serotonin transporter linked polymorphic region, and child maltreatment on diurnal cortisol regulation and internalizing symptomatology. Dev Psychopathol 23: 1125-1138.

Coplan JD, Andrews MW, Rosenblum LA, Owens MJ, Friedman S, Gorman JM et al (1996). Persistent elevations of cerebrospinal fluid concentrations of corticotropin-releasing factor in adult nonhuman primates exposed to early-life stressors: implications for the pathophysiology of mood and anxiety disorders. Proc Natl Acad Sci USA 93: 1619-1623.

Curtis AL, Bethea T, Valentino RJ (2006). Sexually dimorphic responses of the brain norepinephrine system to stress and corticotropinreleasing factor. Neuropsychopharmacology 31: 544-554.

Dannlowski U, Stuhrmann A, Beutelmann V, Zwanzger P, Lenzen T, Grotegerd D et al (2012). Limbic scars: long-term consequences of childhood maltreatment revealed by functional and structural magnetic resonance imaging. Biol Psychiatry 71: 286-293.

De Bellis MD, Keshavan MS (2003). Sex differences in brain maturation in maltreatment-related pediatric posttraumatic stress disorder. Neurosci Biobehav Rev 27: 103-117. 
Dirks A, Groenink L, Schipholt MI, van der Gugten J, Hijzen TH, Geyer MA et al (2002). Reduced startle reactivity and plasticity in transgenic mice overexpressing corticotropin-releasing hormone. Biol Psychiatry 51: 583-590.

Elharrar E, Warhaftig G, Issler O, Sztainberg Y, Dikshtein Y, Zahut $\mathrm{R}$ et al (2013). Overexpression of corticotropin-releasing factor receptor type 2 in the bed nucleus of stria terminalis improves posttraumatic stress disorder-like symptoms in a model of incubation of fear. Biol Psychiatry 74: 827-836.

Everaerd D, Gerritsen L, Rijpkema M, Frodl T, van Oostrom I, Franke B et al (2012). Sex modulates the interactive effect of the serotonin transporter gene polymorphism and childhood adversity on hippocampal volume. Neuropsychopharmacology 37: 1848-1855.

Grillon C, Baas J (2003). A review of the modulation of the startle reflex by affective states and its application in psychiatry. Clin Neurophysiol 114: 1557-1579.

Groenink L, Dirks A, Verdouw PM, de Graaff M, Peeters BW, Millan MJ et al (2008). CRF1 not glucocorticoid receptors mediate prepulse inhibition deficits in mice overexpressing CRF. Biol Psychiatry 63: 360-368.

Hammen C, Henry R, Daley SE (2000). Depression and sensitization to stressors among young women as a function of childhood adversity. J Consult Clin Psychol 68: 782-787.

Hauger RL, Risbrough V, Oakley RH, Olivares-Reyes JA, Dautzenberg FM (2009). Role of CRF receptor signaling in stress vulnerability, anxiety, and depression. Ann NY Acad Sci 1179: 120-143.

Heim C, Nemeroff CB (2001). The role of childhood trauma in the neurobiology of mood and anxiety disorders: preclinical and clinical studies. Biol Psychiatry 49: 1023-1039.

Howerton AR, Roland AV, Fluharty JM, Marshall A, Chen A, Daniels D et al (2014). Sex differences in corticotropin-releasing factor receptor-1 action within the dorsal raphe nucleus in stress responsivity. Biol Psychiatry 75: 873-883.

Kessler RC, Ruscio AM, Shear K, Wittchen HU (2010). Epidemiology of anxiety disorders. Curr Topics Behav Neurosci 2: 21-35.

Koenen KC, Widom CS (2009). A prospective study of sex differences in the lifetime risk of posttraumatic stress disorder among abused and neglected children grown up. J Trauma Stress 22: $566-574$.

Kolber BJ, Boyle MP, Wieczorek L, Kelley CL, Onwuzurike CC, Nettles SA et al (2010). Transient early-life forebrain corticotropin-releasing hormone elevation causes long-lasting anxiogenic and despair-like changes in mice. J Neurosci 30: 2571-2581.

Lebow M, Neufeld-Cohen A, Kuperman Y, Tsoory M, Gil S, Chen A (2012). Susceptibility to PTSD-like behavior is mediated by corticotropin-releasing factor receptor type 2 levels in the bed nucleus of the stria terminalis. J Neurosci 32: 6906-6916.

Lee R, Geracioti TD Jr, Kasckow JW, Coccaro EF (2005). Childhood trauma and personality disorder: positive correlation with adult CSF corticotropin-releasing factor concentrations. Am J Psychiatry 162: 995-997.

McEuen JG, Semsar KA, Lim MA, Bale TL (2009). Influence of sex and corticotropin-releasing factor pathways as determinants in serotonin sensitivity. Endocrinology 150: 3709-3716.

Michalon A, Koshibu K, Baumgartel K, Spirig DH, Mansuy IM (2005). Inducible and neuron-specific gene expression in the adult mouse brain with the rtTA2S-M2 system. Genesis 43: 205-212.

Orr SP, Metzger LJ, Pitman RK (2002). Psychophysiology of posttraumatic stress disorder. Psychiatr Clin North Am 25: 271-293.
Plotsky PM, Thrivikraman KV, Nemeroff CB, Caldji C, Sharma S, Meaney MJ (2005). Long-term consequences of neonatal rearing on central corticotropin-releasing factor systems in adult male rat offspring. Neuropsychopharmacology 30: 2192-2204.

Radulovic J, Ruhmann A, Liepold T, Spiess J (1999). Modulation of learning and anxiety by corticotropin-releasing factor (CRF) and stress: differential roles of CRF receptors 1 and 2. J Neurosci 19: 5016-5025.

Regev L, Tsoory M, Gil S, Chen A (2012). Site-specific genetic manipulation of amygdala corticotropin-releasing factor reveals its imperative role in mediating behavioral response to challenge. Biol Psychiatry 71: 317-326.

Risbrough VB, Hauger RL, Pelleymounter MA, Geyer MA (2003). Role of corticotropin releasing factor (CRF) receptors 1 and 2 in CRF-potentiated acoustic startle in mice. Psychopharmacology 170: 178-187.

Risbrough VB, Hauger RL, Roberts AL, Vale WW, Geyer MA (2004). Corticotropin-releasing factor receptors CRF1 and CRF2 exert both additive and opposing influences on defensive startle behavior. J Neurosci 24: 6545-6552.

Risbrough VB, Masten VL, Caldwell S, Paulus MP, Low MJ, Geyer MA (2006). Differential contributions of dopamine D1, D2, and $\mathrm{D} 3$ receptors to MDMA-induced effects on locomotor behavior patterns in mice. Neuropsychopharmacology 31: 2349-2358.

Sarapas C, Cai G, Bierer LM, Golier JA, Galea S, Ising M et al (2011). Genetic markers for PTSD risk and resilience among survivors of the World Trade Center attacks. Dis Markers 30: 101-110.

Scharf SH, Liebl C, Binder EB, Schmidt MV, Muller MB (2011). Expression and regulation of the Fkbp5 gene in the adult mouse brain. PLoS One 6: e16883.

Skelton K, Ressler KJ, Norrholm SD, Jovanovic T, Bradley-Davino B (2012). PTSD and gene variants: new pathways and new thinking. Neuropharmacology 62: 628-637.

Smoller JW, Rosenbaum JF, Biederman J, Kennedy J, Dai D, Racette SR et al (2003). Association of a genetic marker at the corticotropin-releasing hormone locus with behavioral inhibition. Biol Psychiatry 54: 1376-1381.

Tolin DF, Foa EB (2006). Sex differences in trauma and posttraumatic stress disorder: a quantitative review of 25 years of research. Psychol Bull 132: 959-992.

Toth M, Gresack JE, Bangasser DA, Plona Z, Valentino RJ, Flandreau EI et al (2014). Forebrain-specific CRF overproduction during development is sufficient to induce enduring anxiety and startle abnormalities in adult mice. Neuropsychopharmacology 39: 1409-1419.

Van Pett K, Viau V, Bittencourt JC, Chan RK, Li HY, Arias C et al (2000). Distribution of mRNAs encoding CRF receptors in brain and pituitary of rat and mouse. J Comp Neurol 428: 191-212.

van Zuiden M, Geuze E, Willemen HL, Vermetten E, Maas M, Amarouchi K et al (2012). Glucocorticoid receptor pathway components predict posttraumatic stress disorder symptom development: a prospective study. Biol Psychiatry 71: 309-316.

Vicentini E, Arban R, Angelici O, Maraia G, Perico M, Mugnaini M et al (2009). Transient forebrain over-expression of CRF induces plasma corticosterone and mild behavioural changes in adult conditional CRF transgenic mice. Pharmacol Biochem Behav 93: $17-24$.

Weathington JM, Hamki A, Cooke BM (2014). Sex- and regionspecific pubertal maturation of the corticotropin-releasing factor receptor system in the rat. J Comp Neurol 522: 1284-1298.

Yehuda R, Cai G, Golier JA, Sarapas C, Galea S, Ising M et al (2009). Gene expression patterns associated with posttraumsatic stress disorder following exposure to the World Trade Center attacks. Biol Psychiatry 66: 708-711.

Supplementary Information accompanies the paper on the Neuropsychopharmacology website (http://www.nature.com/npp) 